\title{
Effect of hydrolysable and condensed tannins on growth, morphology and metabolism of Streptococcus gallolyticus (S. caprinus) and Streptococcus bovis
}

\author{
L. O’Donovant and J. D. Brooker
}

\begin{abstract}
Author for correspondence: J. D. Brooker. Tel: +61 88303 7357. Fax: +618 83037114.
\end{abstract} e-mail: john.brooker@adelaide.edu.au

Animal Science

Department, University of

Adelaide, Roseworthy

Campus, Roseworthy,

SA 5371, Australia
Streptococcus gallolyticus (S. caprinus) was resistant in vitro to at least $7 \%$ (w/v) tannic acid and $4 \%(w / v)$ acacia condensed tannin, levels 10-fold greater than those tolerated by S. bovis. Growth of S. gallolyticus in liquid medium was characterized by a lag period which increased, and a growth rate which decreased, with increasing tannin concentration. S. gallolyticus was also more tolerant to the presence of simple phenolic acid monomers than was $S$. bovis, but the lag period was still concentration dependent. Gallate decarboxylase activity in S. gallolyticus was elevated in the presence of tannic acid or gallic acid but not with other phenolic acids. Scanning electron microscopic analysis showed that both the size and shape of $S$. gallolyticus and $S$. bovis changed in response to tannin but only $S$. gallolyticus was surrounded by an extracellular polysaccharide matrix which accumulated in a tannin-concentration-dependent fashion. Washing of the cells to remove extracellular polysaccharide increased the lag period of $S$. gallolyticus in the presence of $1 \%(w / v)$ tannic acid from $4 \mathrm{~h}$ to $6 \mathrm{~h}$. In contrast, increasing extracellular polysaccharide synthesis in $S$. bovis did not increase its tolerance to tannic acid. These data demonstrate that S. gallolyticus has developed a number of mechanisms to reduce the potential effect of tannins on cell growth, and that these mechanisms provide the organism with a selective advantage over $S$. bovis when grown in the presence of tannins.

Keywords: Streptococcus caprinus, hydrolysable tannins, extracellular polysaccharide matrix, tannin resistance, livestock

\section{INTRODUCTION}

Tannins are widespread in the plant kingdom, and are often found in woody, lignified tissues (Haslam, 1989). Condensed tannins (CT) are widely distributed in legume pasture species such as Lotus corniculatus (birdsfoot trefoil), Lotus pedunculatus (greater lotus), Onobrychis viciifolia (sainfoin), in several species of acacia (Degen et al., 1995), in sorghum grain (Kumar \& Singh, 1984) and in many other plant species.

Tannins form weak, $\mathrm{pH}$-dependent and reversible

† Present address: Department of Pathology, University of Tasmania, Hobart, Tas 7000, Australia.

Abbreviations: $\mathrm{CT}$, condensed tannin; $\mathrm{ACT}$, acacia condensed tannin; EM, extracellular matrix; EPS, extracellular polysaccharide; $\mathrm{mBHI}$, modified brain heart infusion; TA, tannic acid. associations with a range of substrates including cellulose, proteins (Hagerman \& Klucher, 1986), enzymes (Kumar \& Singh, 1984), fats, nucleic acids and amino acids (Mole \& Waterman, 1987), often making the substrate resistant to microbial attack. Several reports have suggested that the presence of CT at $<6 \%$ dry matter of the herbivore diet may result in improved animal performance (Barry \& Manley, 1986) because less plant protein is lost as ammonia during ruminal digestion. More protein, therefore, passes to the abomasum and small intestine, where dissociation of tannin-protein complexes can occur under acidic conditions (McSweeney et al., 1988). In addition, the precipitation of soluble proteins effectively removes one of the primary factors involved in foam stabilization, and thus reduces the likelihood of legume bloat (Waghorn et al., 1990; Barry \& McNabb, 1999). 
In contrast, detrimental effects of CT in excess of $6 \%$ dry matter include decreased growth rate and body weight gain, perturbation of mineral absorption, and inhibition of digestive enzymes (Butler, 1992; Yan \& Bennick, 1995; Wood \& Plumb, 1995). Kumar \& Vaithiyanathan (1990) have proposed that tannins inhibit rumen microbial function directly, by complexing with the bacterial cell envelope, or indirectly, by reducing the availability of protein nitrogen and sulphur for microbial use. Either would reduce the rate of plant fibre degradation in the rumen.

Animals that regularly browse CT-containing plants have developed resistance to tannins, at least partly through the presence of tannin-resistant ruminal microorganisms (Bernays et al., 1989). Tannins have also been reported to induce changes in the morphology of several species of ruminal bacteria (Jones et al., 1994; McAllister et al., 1994). Electron microscopy indicated that sainfoin proanthocyanidins were bound to cell coat polymers in Streptococcus bovis, Butyrivibrio fibrisolvens, Prevotella ruminicola and Ruminobacter amylophilis but abnormal cell growth and division was observed only in S. bovis and B. fibrisolvens (Jones et al., 1994). P. ruminicola cells grown with CT were interconnected by condensed extracellular material which was absent from cells grown without CT. Bae et al. (1993) reported that Fibrobacter succinogenes S85 cells grown in the presence of CT also possessed large amounts of electron-dense surface-associated material.

The degradation of tannins in the absence of molecular oxygen has also been documented (Evans \& Fuchs, 1988; Fuchs et al., 1994), and several ruminal microorganisms that can degrade phenolic monomers have been isolated. Eubacterium oxidoreducens degrades gallate, phloroglucinol and pyrogallol to acetate and butyrate in the presence of hydrogen and formic acid (Krumholz \& Bryant, 1986). Tsai \& Jones (1975) isolated bovine ruminal streptococcus and coprococcus strains that were capable of degrading phloroglucinol. A strain of Selenomonas ruminantium that expresses tannin acylhydrolase activity (Skene \& Brooker, 1995) and Streptococcus gallolyticus (S. caprinus) (Nelson et al., 1995, 1998; Sly et al., 1997) have been isolated from feral goat rumen samples, the latter being resistant to tannic acid (TA) at concentrations of up to $7 \%(\mathrm{w} / \mathrm{v})$ and to CT up to $4 \%(\mathrm{w} / \mathrm{v})$. In contrast, growth of the more common ruminal streptococcus, S. bovis, was inhibited by tannins at concentrations 10 -fold lower (Brooker et al., 1994). In this study we investigated CT and TA resistance by S. gallolyticus and S. bovis, and we describe two mechanisms, expression of gallate decarboxylase activity and secretion of extracellular polysaccharide, by which $S$. gallolyticus gains a growth advantage.

\section{METHODS}

Bacterial strains and culture conditions. Streptococcus bovis type 2B was obtained from K. Gregg, University of New England, NSW, Australia. Streptococcus gallolyticus (for- merly $S$. caprinus) type strain 2.2 was originally isolated in our laboratory and is available through the Australian Collection of Microorganisms (ACM 3968). Modified Brain Heart Infusion (mBHI) medium and minimal medium (NB) were prepared anaerobically as described by Brooker et al. (1994) and Nili \& Brooker (1995), respectively. Crude extracts of acacia CT (ACT) were supplied by P. Martin, Queensland Department of Primary Industries, Brisbane, Queensland, Australia, by extracting acacia leaves with $70 \%(\mathrm{v} / \mathrm{v})$ acetone/ water according to the method of Broadhurst \& Jones (1978). ACT and TA (Sigma) were stored under anaerobic conditions, and stock solutions as well as $p$-coumaric, ferulic, cinnamic, sinapic, syringic, gallic, ellagic and vanillic acids (Sigma) were prepared immediately prior to use in anaerobic dilution solution (Ogimoto \& Imai, 1984). Tannin solutions were neutralized, filter-sterilized and added to broth cultures in Hungate tubes.

Hungate tubes containing $10 \mathrm{ml}$ medium were inoculated under anaerobic conditions $\left(95 \% \mathrm{CO}_{2} / 5 \% \mathrm{H}_{2}\right)$ and incubated at $39^{\circ} \mathrm{C}$. Bacterial growth in the absence of tannins was monitored as $\mathrm{OD}_{600}$ using a spectrophotometer (LKB Biochrom NOVASPEC) that had been modified for Hungate tubes. In the presence of tannins, growth was quantified on $\mathrm{mBHI}$ agar plates by serial dilution and viable colony counts.

Gallic acid decarboxylase assay. Bacteria were grown in $\mathrm{mBHI}$ alone or supplemented with $1.0 \%(\mathrm{w} / \mathrm{v})$ TA or gallic acid, or $0.5 \%(\mathrm{w} / \mathrm{v})$ ACT, ferulic acid or $p$-coumaric acid, and $50 \mu \mathrm{l}$ samples of whole cell suspensions (containing $5 \times 10^{5}$ cells) were added to $1 \mathrm{ml} 0 \cdot 1 \mathrm{M}$ sodium phosphate buffer (pH 6.8), $2.5 \mathrm{mM}$ dithiothreitol, $10 \mathrm{mM} \mathrm{MgCl}$ in a quartz glass cuvette and warmed at $37^{\circ} \mathrm{C}$ for $5 \mathrm{~min}$. Gallate decarboxylase activity was initiated by adding $0.5 \mathrm{ml} 0.5 \%$ $(\mathrm{w} / \mathrm{v})$ gallic acid or TA dissolved in $0 \cdot 1 \mathrm{M}$ phosphate buffer $(\mathrm{pH} \mathrm{6.8)}$. The reaction was monitored at $300 \mathrm{~nm}$ over a $15 \mathrm{~min}$ period using a spectrophotometer (LKB Biochrom NOVASPEC) positioned in a Coy anaerobic hood. The reaction was linear with time, for at least $20 \mathrm{~min}\left(R^{2}=\right.$ $0 \cdot 9791)$, and with gallic acid in excess of $2 \%(\mathrm{w} / \mathrm{v})\left(R^{2}=\right.$ 0.9883). S. bovis or boiled cells were included as controls. Activity was expressed as mmol phenolic acid decarboxylated $\min ^{-1}$ (mg cell protein $)^{-1}$. To examine the products of the gallate decarboxylase assay, at zero time and up to $20 \mathrm{~min}$ after addition of the substrate, $0 \cdot 1 \mathrm{ml}$ aliquots were removed, extracted with $0.5 \mathrm{ml}$ ethyl acetate and freeze-dried. Trimethylsilyl derivatives of the supernatant were prepared and the samples were analysed with a Hewlett Packard gas chromatograph (GC) fitted with flame ionization detectors and a BP-21 (SGE, 0.25) capillary column.

In liquid cultures, the presence of gallic acid was determined as described by Inoue \& Hagerman (1988). Samples were added to a glass tube containing $0.15 \mathrm{ml}$ methanolic rhodanine solution $(0.667 \% \mathrm{w} / \mathrm{v}$ rhodanine in $100 \%$ methanol). After exactly $5 \mathrm{~min}, 0.1 \mathrm{ml} 0.5 \mathrm{M} \mathrm{KOH}$ was added, and after a further $2.5 \mathrm{~min}$, the mixture was diluted to $2.5 \mathrm{ml}$ with $\mathrm{H}_{2} \mathrm{O}$. The $A_{520}$ was measured after $10 \mathrm{~min}$ using a Shimadzu UV$160 \mathrm{~A}$ spectrophotometer and quartz glass cuvettes $(1.0 \mathrm{~cm}$ light path). Gallic acid and pyrogallol were also analysed by GC-mass spectrometry (GC-MS). Pyridine (0.25 ml, Sigma) and N-O-bis(trimethylsilyl)trifluoracetamide (BSTFA, $0.25 \mathrm{ml}$, Sigma) were added and the mixture was allowed to stand for $30 \mathrm{~min}$ at room temperature. The samples were diluted in chloroform prior to analysis by GC-MS on the Hewlett Packard GC (see above). Mass spectra were obtained in the electron-impact mode and the chemical ionization mode; masses were scanned from 50 to 650 in $0.5 \mathrm{~s}$; 
chromatograms were recorded and peak areas were integrated with a Hewlett Packard reporting integrator and identified by comparison with the internal library and authentic standards.

Lactic acid determination. Lactate present in culture supernatants was determined on a Shimadzu 14A GC plus the Delta Data System (SGE Analytical Products), equipped with a bonded phase capillary column (BP21: 0.5 $\mu \mathrm{m}$ film, $0.25 \mathrm{~m} \times 0.53 \mathrm{~mm}$ i.d., SGE) and using caproic acid as an internal standard. A calibration standard contained lactic, succinic and caproic acids.

Removal of extracellular polysaccharide (EPS) from cells. A $10 \mathrm{ml}$ overnight culture of $S$. gallolyticus grown in the presence of $1 \%(\mathrm{w} / \mathrm{v})$ TA was centrifuged at $12000 \mathrm{~g}$ for $30 \mathrm{~min}$ and the cell pellet was suspended in an equal volume of $1.5 \mathrm{mM}$ sodium acetate, $\mathrm{pH} 4 \cdot 2$. The cells were mixed thoroughly to remove attached EPS (as described by Whitfield, 1988) and then recentrifuged. The cell pellet was resuspended in $5 \mathrm{ml}$ fresh medium and a $50 \mu \mathrm{l}$ aliquot was used to inoculate fresh medium. To determine the effect of TA on the production of EPS by S. gallolyticus and S. bovis, cells were grown for $48 \mathrm{~h}$ in $\mathrm{mBHI}$ medium supplemented with increasing concentrations of TA. The TA was removed by precipitation with $1 \%(\mathrm{w} / \mathrm{v})$ polyvinyl pyrrolidone and overnight dialysis against CE buffer (50 mM Na $\mathrm{CO}_{3}, 25 \mathrm{mM}$ EDTA), pH 9.5. The EPS (expressed as glucose equivalents) was expressed as mg EPS per mg dry weight of cells (after removal of EPS).

Field emission scanning electron microscopy. S. gallolyticus or $S$. bovis was grown in $\mathrm{mBHI}$ medium in the presence of increasing concentrations of TA, ACT, gallic acid, ferulic acid, $p$-coumaric acid and pyrogallol. Throughout bacterial growth, samples were removed and the cells were centrifuged at $3000 \mathrm{~g}$ for $10 \mathrm{~min}$. Cells were resuspended in fixative solution (Karnovsky, 1965) containing $0 \cdot 15 \%(\mathrm{w} / \mathrm{v})$ ruthenium red (Frehel et al., 1988), and incubated at room temperature for $1 \mathrm{~h}$. The cell suspension was centrifuged as above and the cells were washed twice ( $30 \mathrm{~min}$ each) in phosphate-buffered saline (PBS) containing $4 \%$ sucrose and $0.05 \%$ ruthenium red. The pellets were fixed for $2 \mathrm{~h}$ with $2 \%$ aqueous osmium tetroxide (ProSciTech) containing $0.05 \%$ ruthenium red. The cells were dehydrated through a graded series of ethanol solutions $(50,70,90,95$ and $100 \%)$ with a final change of $1 \mathrm{~h}$ in $100 \%$ ethanol at room temperature. The samples were infiltrated with Peldri II (ProSciTech) and ethanol in the ratios of $1: 1$ and $2: 1$ and with $100 \%$ Peldri II for $45 \mathrm{~min}$ each, before being spotted onto aluminium scanning electron microscopy stubs (ProSciTech) and dried under vacuum. The samples were coated with gold-palladiumcarbon and examined using a Philips XL30 field emission scanning electron microscope operated at $15 \mathrm{kV}$.

Transmission electron microscopy. Bacterial cells were prepared as above, except that they were washed in CE buffer (50 $\mathrm{mM} \mathrm{Na}_{2} \mathrm{CO}_{3}, 25 \mathrm{mM}$ EDTA), $\mathrm{pH} 10$ and infiltrated with Spurr low-viscosity embedding resin (Spurr, 1969) and ethanol in the ratios of $1: 1,2: 1$ and $100 \%$ resin for $45 \mathrm{~min}$ each. The cells were placed in $1 \mathrm{ml}$ fresh $100 \%$ Spurr resin and polymerized at $60{ }^{\circ} \mathrm{C}$ for $24 \mathrm{~h}$. Embedded preparations were sectioned with a diamond knife $(70 \mu \mathrm{m})$ using a Leica Reichert Ultracut E microtome and placed on collodion-coated 400mesh copper grids. The sections were stained with $2 \%(\mathrm{w} / \mathrm{v})$ aqueous uranyl acetate (ProSciTech) for $20 \mathrm{~min}$ followed by $2.66 \%(\mathrm{w} / \mathrm{v})$ lead citrate for $5 \mathrm{~min}$ (Reynolds, 1963), and were examined using a Philips CM100 transmission electron microscope at an accelerating voltage of $60 \mathrm{kV}$. Images were recorded on Kodak no. 4489 electron microscope film.
Statistical analyses. Differences in the levels of tolerance to phenolic acids between $S$. gallolyticus or S. bovis, in cell and capsule sizes and in the amount of EPS produced by the bacteria were determined using Student's $t$-test. Slopes of exponential growth, determined by linear regression analysis, are reported as the growth rates and were analysed using analysis of variance for organisms-by-phenolic concentration interactions.

\section{RESULTS}

\section{Comparative growth in vitro of S. gallolyticus and $S$. bovis in tannin-containing medium}

Because of interference of tannins with optical density measurements, minimum inhibitory concentrations of TA and ACT for growth of S. gallolyticus and S. bovis in broth with or without TA or ACT were determined from colony counts of cell dilutions plated and grown in the absence of tannins. S. gallolyticus grew in up to
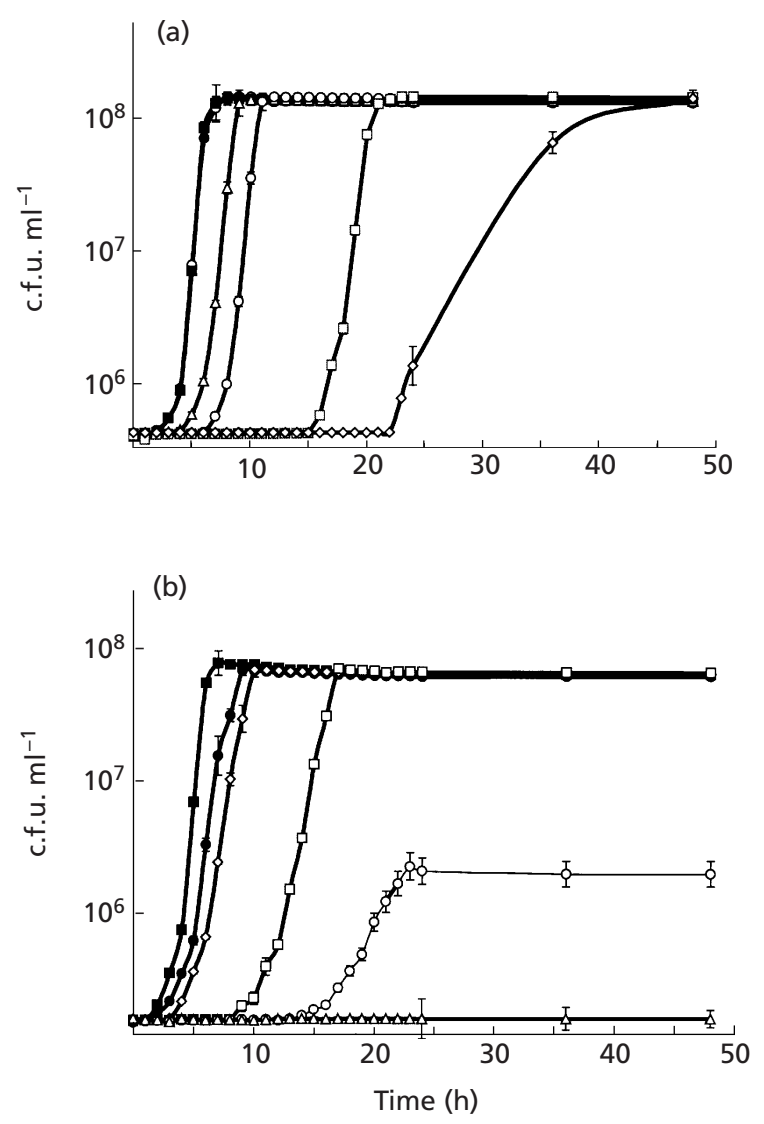

Fig. 1. Effect of TA on the growth of $S$. gallolyticus (a) and $S$. bovis (b). Bacteria were incubated in $\mathrm{mBHI}$ medium supplemented with increasing concentrations of TA. At regular time intervals, samples were removed and growth was determined on $\mathrm{mBHI}$ plates by serial dilution and viable cell count. Points represent the means of triplicate trials; bars represent the standard error. Tannic acid concentrations (\%, $\mathrm{w} / \mathrm{v})$ : (a) $0(\square), 0.5(\bullet), 1.0+(\triangle), 2.0+(\bigcirc), 3.0+(\square), 5.0+(\diamond)$; (b) $0(\square), 0.1+(\bullet), 0.2+(\diamond), 0.5+(\square), 0.75+(\bigcirc), 1.0+(\triangle)$ [†Growth significantly different from control (no TA), $P<0.01]$. 


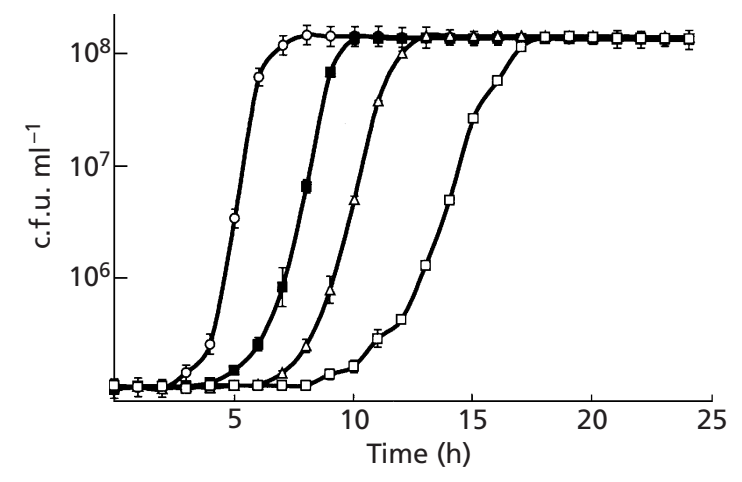

Fig. 2. Effect of $A C T$ on the growth of $S$. gallolyticus. Bacteria were incubated in $\mathrm{mBHI}$ medium supplemented with increasing concentrations of ACT. At regular time intervals, aliquots were removed and growth was determined on $\mathrm{mBHI}$ plates by serial dilution and viable cell count. Points represent the means of triplicate trials; bars represent the standard error. ACT concentration $(\%, w / v)$ : $0(O), 0.5+(\square), 1.0+(\triangle), 2.0(\square)$ [†Significant difference from control (no ACT), $P<0.05$ ].

$7 \cdot 0 \%$ TA or $4.0 \%$ ACT whereas $S$. bovis growth was inhibited by TA or ACT concentrations greater than $0.5 \%$. This response was consistent in either $\mathrm{mBHI}$ medium or completely defined NB medium containing $\mathrm{NH}_{4} \mathrm{Cl}$ as the sole nitrogen source.

Differences in lag periods were observed as the concentration of TA or ACT in the medium was increased. For $S$. bovis, growth in $0 \cdot 1,0 \cdot 2,0.5$ and $0.75 \%$ TA was preceded by a lag period of $2,3,8$ and $16 \mathrm{~h}$, respectively (Fig. 1b). S. gallolyticus grew with mean lag times of 4 , 7,16 and $23 \mathrm{~h}$ for TA concentrations of $1 \cdot 0,2 \cdot 0,3 \cdot 0$ and $5.0 \%$ (Fig. 1a). In the presence of up to $2.0 \%$ ACT, the lag period was $10 \mathrm{~h}$ (Fig. 2). Inoculation of fresh medium containing $2.0 \%$ TA with overnight TA cultures of $S$. gallolyticus or S. bovis decreased the lag time for both bacteria, although there was no change in the maximum tolerable level of tannin (results not shown).

The exponential growth rate of $S$. gallolyticus remained unaffected by the addition of TA or ACT up to concentrations of $1 \%$; above this concentration, however, growth rates were significantly reduced. In $3 \%$ TA or $2 \%$ ACT, the growth rate of $S$. gallolyticus was reduced by $20-25 \%$, whereas the growth rate of $S$. bovis was reduced by $50 \%$ and $85 \%$ in medium containing $0.5 \%$ and $0.75 \%$ TA respectively.

\section{Growth in the presence of other phenolic acids}

Tolerance of $S$. gallolyticus and S. bovis to a range of phenolic monomers, including $p$-coumaric, ferulic, cinnamic, sinapic, syringic, gallic, ellagic and vanillic acids, was investigated. Neither organism was able to utilize any of the phenolic monomers as a sole carbon source (as determined by lack of growth on nutrient agar plates or in broth containing the phenolic acids as the sole source of fermentable carbon), and in the presence of

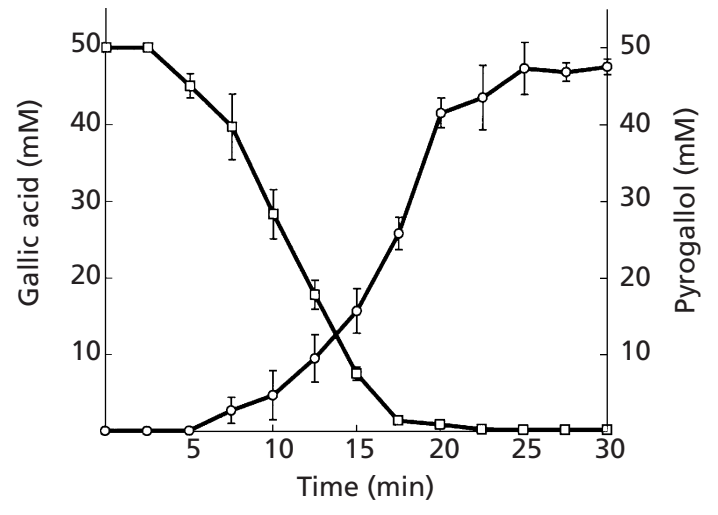

Fig. 3. Degradation of gallic acid ( $\square$ ) and corresponding pyrogallol production $(O)$ by $S$. gallolyticus. Bacteria were incubated in $\mathrm{BHI}$ medium containing $50 \mathrm{mM}$ gallic acid at $25^{\circ} \mathrm{C}$ for $30 \mathrm{~min}$ and samples were analysed by GC. Points represent the means of triplicate trials; bars represent the standard error.

glucose, all monomers inhibited growth of both bacterial species at concentrations $>4 \%$.

\section{Effect of TA on lactate production}

Clearing zones were previously described (Brooker et al., 1994) surrounding colonies of $S$. gallolyticus but not $S$. bovis growing on TA-containing nutrient agar plates. These may be due to lactic-acid-mediated hydrolysis of the tannin-protein complexes that form in the medium. The concentration of lactic acid produced in broth cultures at the end of exponential phase was therefore measured. In the presence of $0.5 \%$ TA (S. bovis) or $2 \%$ TA (S. gallolyticus), the lactate concentrations were not significantly different $(18.2$ and $19.7 \mathrm{mM}$ lactate, respectively).

\section{Degradation of TA}

Degradation of TA can occur by hydrolysis of ester and depside bonds, yielding gallic acid, which can be decarboxylated by gallate decarboxylase to yield pyrogallol. This has been demonstrated in a number of bacterial systems (Krumholz \& Bryant, 1986; Brune \& Schink, 1992). In medium containing $1 \%$ TA, $0.6 \mathrm{mg}$ gallic acid $\mathrm{ml}^{-1}$ was detected prior to inoculation with bacteria. After 16-20 h incubation, either in the presence of $S$. bovis or in the absence of bacteria, this spontaneous release of gallic acid into the medium had increased to $3.2 \mathrm{mg} \mathrm{ml}^{-1}$. In contrast, after incubation with $S$. gallolyticus, the gallic acid concentration increased from 0.6 to $7.8 \mathrm{mg} \mathrm{ml}^{-1}(P<0.05)$. To determine whether gallic acid was transformed by $S$. gallolyticus, samples from a broth culture containing $1.0 \%$ gallic acid were analysed. The results (Fig. 3) show that gallic acid disappeared during the incubation, coinciding with the appearance of pyrogallol. There was no evidence that pyrogallol was degraded further, and addition of pyro- 
Table 1. Gallate decarboxylase activity in S. gallolyticus after growth in the presence of phenolic compounds

Gallate decarboxylase activity was determined in whole-cell suspensions prepared from $S$. gallolyticus grown in $\mathrm{mBHI}$ and $\mathrm{mBHI}$ supplemented with the phenolic acids listed. Results are the means of triplicate trials \pm the standard error.

\begin{tabular}{|lcc|}
\hline Medium & $\begin{array}{c}\text { Gallate decarboxylase activity } \\
\left(\mathbf{m m o l} \text { pyrogallol } \mathbf{~ m i n}^{-1} \mathbf{~ m g}^{-1}\right)\end{array}$ & $\begin{array}{c}\text { Relative } \\
\text { change }\end{array}$ \\
\hline mBHI & $2 \cdot 63 \pm 0 \cdot 02$ & $1 \cdot 00$ \\
mBHI $+1 \cdot 0 \%$ TA & $6 \cdot 44 \pm 0 \cdot 18^{* *}$ & $2 \cdot 45$ \\
mBHI $+1 \cdot 0 \%$ gallic acid & $10 \cdot 96 \pm 0 \cdot 22^{*}$ & $4 \cdot 17$ \\
mBHI $+0.5 \%$ ACT & $3 \cdot 28 \pm 0 \cdot 04$ & $1 \cdot 24$ \\
mBHI $+0 \cdot 5 \%$ ferulic acid & $2 \cdot 39 \pm 0 \cdot 05$ & $0 \cdot 91$ \\
mBHI $+0.5 \%$ p-coumaric acid & $2 \cdot 56 \pm 0 \cdot 03$ & $0 \cdot 97$ \\
Boiled cells (control) & $0 \cdot 14 \pm 0 \cdot 003$ & - \\
\hline
\end{tabular}

* Significantly different from control (no phenolic acid), $P<0 \cdot 05$.

gallol to culture medium had no effect on growth of $S$. gallolyticus or S. bovis. The rate of decarboxylation of gallic acid by $S$. gallolyticus was calculated to be $2 \cdot 63 \pm 0.02 \mathrm{mmol} \mathrm{min}^{-1}$ (mg bacterial protein) ${ }^{-1}$, but only in whole-cell preparations under strictly anaerobic conditions. Growth of S. gallolyticus, gallic acid decomposition and pyrogallol production occurred together, with stoichiometric conversion of $50 \mu \mathrm{mol}$ gallic acid $\mathrm{ml}^{-1}$ to $47 \mu \mathrm{mol}$ pyrogallol $\mathrm{ml}^{-1}$. S. bovis was unable to degrade gallic acid.

In contrast, growth of $S$. gallolyticus (or S. bovis) in the presence of the carboxylated compounds protocatechuic acid, 3,5-dihydroxybenzoic acid and hydroxybenzoic acid failed to produce their decarboxylated derivatives, catechol, resorcinol and phenol, respectively. When $S$. gallolyticus was grown in mBHI medium containing $1 \%$ TA, gallate decarboxylase activity was increased $2 \cdot 5$ fold compared with controls lacking TA, and $4 \cdot 1$-fold when it was grown in the presence of $1 \%$ gallic acid (significant at $P<0.05$; Table 1 ). However, this did not occur in cells exposed to ACT, ferulic acid or $p$-coumaric acid.

\section{Effect of TA and ACT on bacterial cells}

Light microscopy. Examination of S. gallolyticus and $S$. bovis by phase-contrast microscopy showed homogeneous cocci, occurring mainly in pairs or short chains. Both bacteria stained Gram-positive but this became variable with the addition of tannin. Average chain length was increased two- to threefold in cultures of $S$. bovis when the concentration of TA in the medium was greater than $0 \cdot 2 \%$, or in S. gallolyticus when the TA concentration exceeded $1.5 \%$ (not shown).

Electron microscopy. Using transmission electron microscopy and field emission scanning electron microscopy, $S$. bovis was seen to show increased chain formation and clumping when the TA concentration exceeded $0 \cdot 2 \%$.

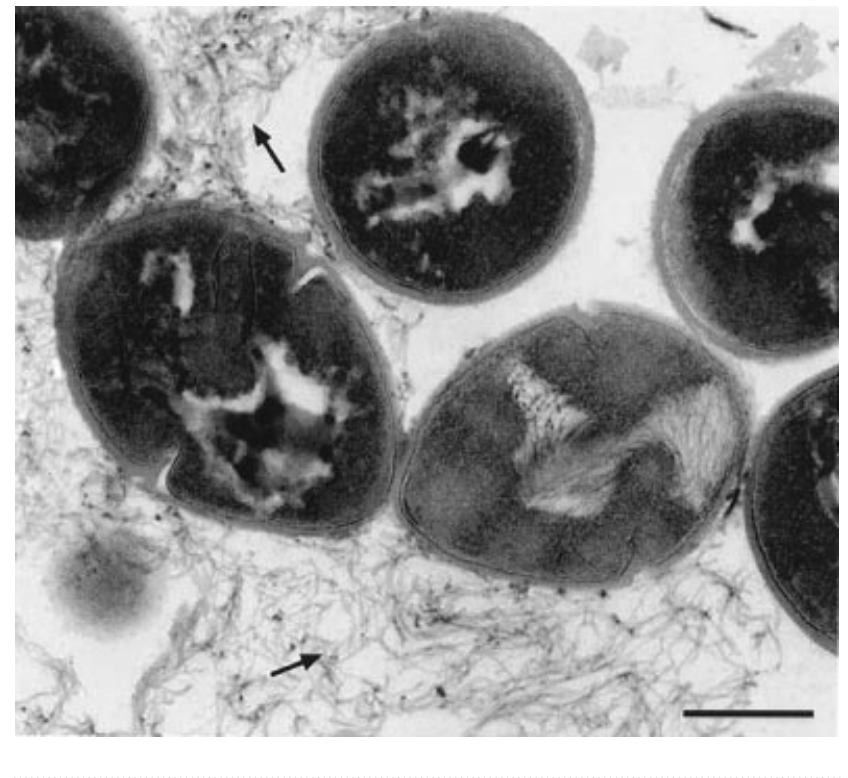

Fig. 4. Transmission electron micrograph of S. gallolyticus after overnight growth in $4 \%$ TA. The arrow indicates extracellular matrix material. Bar, $0.2 \mu \mathrm{m}$.

When the TA concentration was increased to $0.75 \%$, increased numbers of abnormally shaped $S$. bovis cells were observed, and lysed cells were present in every field of view. In some cells, multiple divisional planes suggested that the cells were undergoing unusual or incomplete cell division, and blebs were visible on the cell surface (not shown). In contrast, the size and shape of $S$. gallolyticus cells were unaffected by the presence of ACT or TA until concentrations reached 2.5 and $3.0 \%$ respectively. Concentrations greater than these produced changes similar to those observed in S. bovis, although no abnormal cell divisions were detected and minimal cell lysis was observed. 


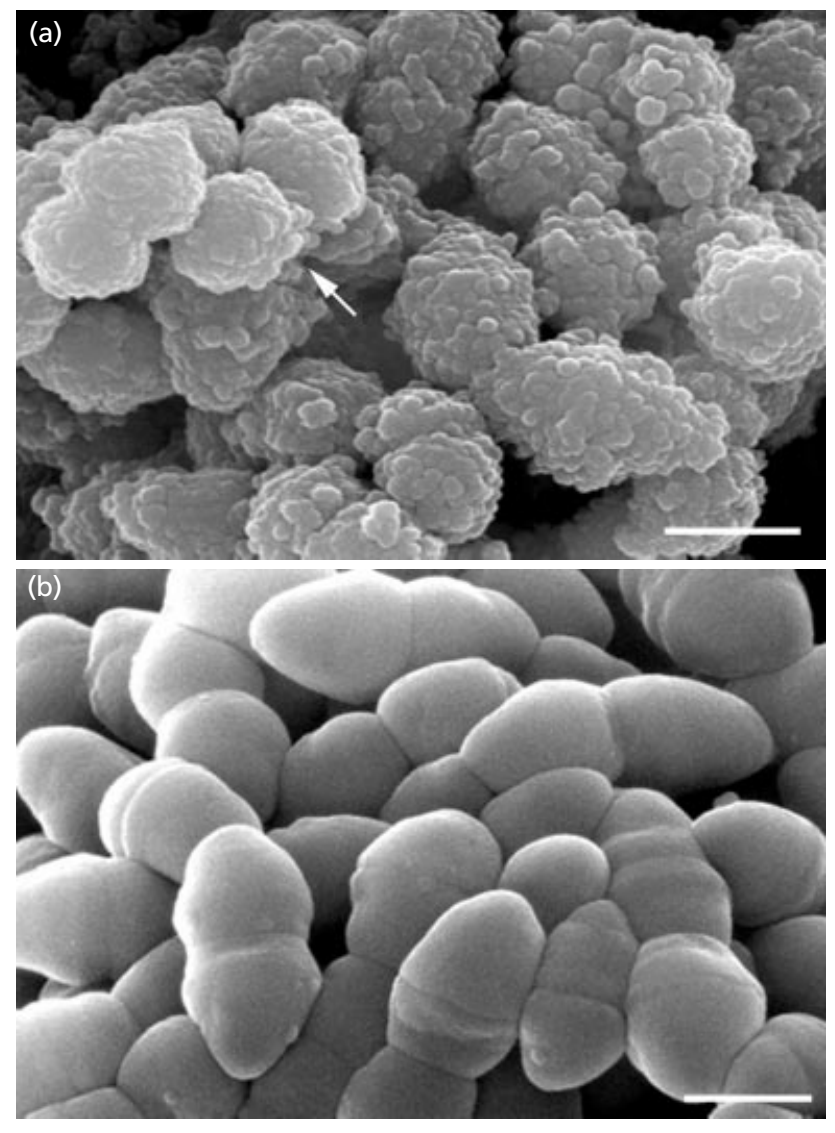

Fig. 5. Field emission scanning electron micrographs of $S$. gallolyticus after overnight growth in $\mathrm{mBHI}$ medium in the presence (a) or absence (b) of $2 \%$ TA. Cells were washed in CE buffer, fixed in glutaraldehyde containing ruthenium red and dehydrated as described in Methods. Preparations were viewed using a Philips XL30 FESEM instrument. The arrow indicates extracellular matrix material. Bars, $1 \mu \mathrm{m}$.

A fibrous matrix extending from the surface of $S$. gallolyticus, but not $S$. bovis, was observed by transmission electron microscopy after growth of the bacteria in TA (Fig. 4) or ACT. When examined using field emission scanning electron microscopy (Fig. 5a, b), the extracellular material was globular and in patches on the surface of $S$. gallolyticus and increased in a concentration-dependent manner such that when the TA concentration exceeded $2 \%$, the extracellular material completely encased the bacterium. In the absence of TA, S. gallolyticus produced little extracellular material.

\section{Characterization of the extracellular matrix}

Extracellular matrix (EM) material was recovered by sodium acetate extraction of $S$. gallolyticus and S. bovis grown in the absence of TA. The mean yield from stationary-phase $S$. gallolyticus was $1 \cdot 25 \pm 0 \cdot 12 \mathrm{mg}$ EM $(\mathrm{mg} \text { cells) })^{-1}$ (dry weight of cells after removal of EM) compared with $1.30 \pm 0.06 \mathrm{mg}$ EM $\left(\mathrm{mg}\right.$ cells) ${ }^{-1}$ isolated

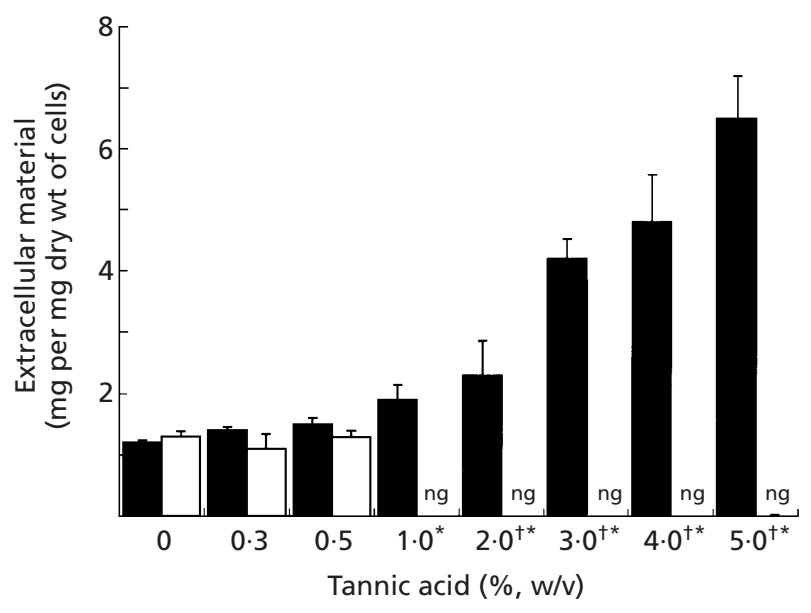

Fig. 6. Effect of TA on the production of extracellular matrix by S. gallolyticus ( $\square$ ) and S. bovis ( $\square$ ). Extracellular matrix was isolated from the bacteria after $48 \mathrm{~h}$ growth in $\mathrm{mBHI}$ medium supplemented with increasing concentrations of TA. Data represent the means of triplicate trials; bars represent the standard error. ng, No growth. +Significantly different from control (no TA), $P<0.05$. *Significantly different between bacteria, $P<0.01$.

from S. bovis (Fig. 6), and had a mean molecular mass of $2 \times 10^{6} \mathrm{Da}$.

Colorimetric assays indicated that the material was composed predominantly of carbohydrate. However, analysis of the alditol acetate derivatives by GC and GCMS showed the neutral sugar composition from $S$. gallolyticus and S. bovis to be different. In S. gallolyticus, glucose was primarily present, with trace amounts of mannose (glucose:mannose 1:0·2). Variable amounts $(0-4 \cdot 2 \%)$ of acyl and $N$-acyl residues were also detected. No uronic acids, proteins or hexosamines were found. In S. bovis, the neutral sugar composition was shown to consist of mannose, glucose and galactose in the ratio of $1: 0 \cdot 70 \cdot 2$. Larger amounts of acyl and $N$-acyl groups were detected $(0-7 \cdot 3 \%)$ and uronic acids were also found $(2 \cdot 7 \pm 1 \cdot 2 \%)$. When the bacteria were grown in the presence of TA, no change in the carbohydrate composition occurred although the uronic acids increased in both $S$. gallolyticus and $S$. bovis by $2 \cdot 1 \pm$ $0.9 \%$ and $5.4 \pm 1.5 \%$, respectively.

\section{Effect of tannin on the production of extracellular matrix}

With the addition of $>0.5 \%$ TA or ACT, yields of EM extracted from cultures of $S$. gallolyticus increased significantly $(P<0.05) ; 5 \%$ TA caused a sixfold increase in the amount of EM extractable from $S$. gallolyticus (Fig. 6). In the presence of $2 \%$ ACT, EM increased 2.5-fold (results not shown). Addition of phenolic acids such as gallic acid, $p$-coumaric or ferulic acid had no significant effect on the amount of EM produced by $S$. gallolyticus. To determine whether the 


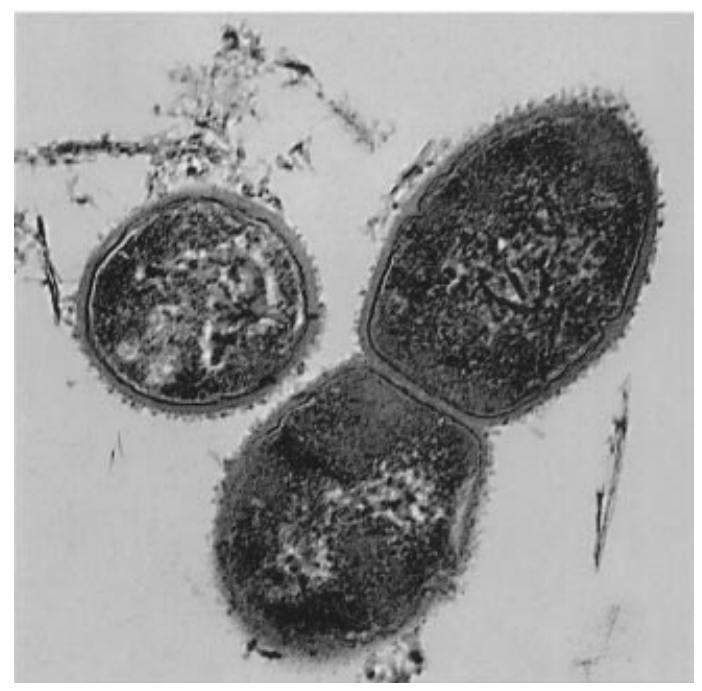

Fig. 7. Effectiveness of washing procedure to remove extracellular matrix from $S$. gallolyticus. Transmission electron micrograph of $S$. gallolyticus, grown with $1 \%$ TA and washed with $1.5 \mathrm{mM}$ sodium acetate, $\mathrm{pH} 4 \cdot 2$. Magnification $\times 20000$.

EM provided a growth advantage to $S$. gallolyticus, cells were washed in sterile $1.5 \mathrm{mM}$ sodium acetate $(\mathrm{pH} 4 \cdot 2)$ to remove some of the EM, before being inoculated into fresh mBHI medium containing $1 \%$ TA. Scanning electron microscopy demonstrated the effectiveness of the washing procedure (Fig. 7). In washed cells, the lag period increased from 4 to $6 \mathrm{~h}$. Control cells grown in the absence of TA and washed as above showed no significant increase in lag period.

S. bovis produces excess EM when grown in the presence of sucrose. To determine whether EM alone would provide protection against TA, S. bovis was grown overnight in $\mathrm{mBHI}$, then diluted and spread on plates containing $5 \%$ sucrose and $0,0 \cdot 2,0 \cdot 5,1 \cdot 0$ or $1 \cdot 5 \%$ TA. In the absence of TA, colonies were extremely slimy, with a spreading morphology. In the presence of $0 \cdot 2 \%$ TA, there was no reduction in the number of c.f.u., and colonies were white and shiny. There was no growth on TA at concentrations $>0.5 \%$.

\section{DISCUSSION}

Growth studies demonstrated that both S. gallolyticus and $S$. bovis were inhibited by the presence of tannins in the medium; this was most clearly reflected by an extended lag phase before exponential growth, and a reduced growth rate. Although both species exhibited an extended lag phase, $S$. bovis was approximately $30-$ fold more sensitive to TA or ACT than S. gallolyticus. At an ACT concentration of $2 \%$, the lag period for $S$. gallolyticus was only slightly increased $(10 \mathrm{~h})$ over that with $2 \%$ TA $(7 \mathrm{~h})$.

These data demonstrate that both species are initially sensitive to tannins and that adaptation by enzyme induction or metabolic transformation of the tannin molecule is required. Only $S$. gallolyticus is able to achieve a level of adaptation to permit continued growth, albeit at a reduced rate, in the presence of $>0.75 \%$ tannins. The fact that the lag period was tannin-concentration dependent suggests that growth in the presence of tannins may be at least partly dependent on metabolic transformation of the tannin molecule or the development of a protective barrier. Resistance to tannins was less likely to be due to acid hydrolysis of tannin-protein complexes, since both $S$. gallolyticus and $S$. bovis produced the same amount of lactic acid yet were differentially affected by both TA and ACT. A reduction in the lag period after reinoculation of tanningrown $S$. gallolyticus supports the view that adaptation is associated with a time-dependent event such as enzyme induction (possibly gallate decarboxylase), and/or the synthesis of EM.

Decreased growth rate is also consistent with the transmission electron microscopy and field emission scanning electron microscopy studies, which showed an increase in chain length and clumping for both $S$. bovis and S. gallolyticus in the presence of TA. The presence of abnormally shaped $S$. bovis but not $S$. gallolyticus was a clear indication of differential toxicity. Similar effects of tannins on the morphology of other species of rumen bacteria have been reported (Jones et al., 1994), although in that work, there was no comparison between tannin-sensitive and tannin-resistant species as described here.

We have demonstrated increased activity of gallate decarboxylase and the accumulation of pyrogallol as a result of exposure of $S$. gallolyticus to TA, but not ACT. Decarboxylation was specific for gallic acid, since related carboxylated compounds were not decarboxylated. Why $S$. gallolyticus catalyses the decarboxylation reaction but does not transform pyrogallol further is not clear, although it is likely that pyrogallol is less toxic than gallic acid, or that its production was thermodynamically favourable for the bacterium, possibly linked with energy generation through proton pumping. Furthermore, since $S$. gallolyticus would normally function in a mixed community, it is likely that other bacterial species could utilize pyrogallol, thus maintaining a thermodynamic equilibrium in favour of gallate decarboxylation. The actual concentration of pyrogallol in the rumen of animals fed a tannin-rich diet is unknown. Evidence for such a community approach is seen in the possible interaction between Selenomonas ruminantium K2, which produces gallic acid from hydrolysis of gallotannins (Skene \& Brooker, 1995), and S. gallolyticus, which decarboxylates gallic acid to form pyrogallol. The lack of response to ACT is not surprising, since ACT contains little or no esterified gallic acid. Other mechanisms of adaptation may, therefore, be involved in resistance to ACT.

The concept of a protective barrier is supported by the scanning electron microscopy studies, which showed that $S$. gallolyticus produces elevated levels of EM in 
response to tannin and that this is found closely associated with the bacterial cell wall. Micro-organisms often secrete an EM that forms a tight, cell-associated (integral) capsule or a dispersed (peripheral) slime consisting of a loose network of unordered fibrils which extend from the cell surface and which can be sloughed off into the aqueous phase (DeVuyst \& Degeest, 1999). In some cases, both capsular and unattached polysaccharides may be produced by the same microbe. Structural diversity in EM therefore arises from a broad range of monosaccharide components and is increased by potential non-carbohydrate substituents and linkage types, usually mixed $\alpha$ - and $\beta$-linkages, in the main chain. Analysis of the EM from $S$. bovis and $S$. gallolyticus showed that the two organisms differed in EM composition, with $S$. gallolyticus containing a lower proportion of mannose than S. bovis. What advantage, if any, this confers on $S$. gallolyticus growing in the presence of tannins is unknown. Removal of EM from $S$. gallolyticus appeared to increase its sensitivity to TA, supporting the view that this material provides a protective barrier to the organism. In contrast, enhancement of EM synthesis by growth of S. bovis in a sucrose-rich medium did not increase its tolerance for TA. Rather, the TA appeared to reduce the secretion of EM compared to the non-TA control. This suggests that EM biosynthesis alone is not enough to provide protection against tannins, and possibly, that induction of gallate decarboxylase is a critical factor in tannin tolerance by $S$. gallolyticus. Changes in production of the glycocalyx of some ruminal bacteria in response to tannins from birdsfoot trefoil have previously been reported (Chiquette et al., 1988), although this was not described in relation to any specific bacterial species.

Protection also appears to be tannin-specific, since incubation with monomeric phenolic acids did not result in adaptation by $S$. gallolyticus and all phenolic acids tested were inhibitory at elevated concentrations $(>4 \%)$. This suggests that initiation of adaptation to tannins may be dependent on molecular size, hydrophobicity, or the ability of the tannin to interact with cellular constituents.

Our results show that $S$. bovis and S. gallolyticus initially respond to TA and ACT in the same way, with an increased lag phase and decreased growth rate, but that $S$. gallolyticus is able to initiate an adaptation response including elevation of gallate decarboxylase and induction of EM biosynthesis. The response enables $S$. gallolyticus to maintain growth and biosynthetic capacity in the presence of tannin concentrations up to 10fold higher than those tolerated by $S$. bovis. This explains the widespread occurrence of $S$. gallolyticus in the rumen of livestock that frequently browse tannincontaining forages (Brooker et al., 1994), and it is likely that the presence of $S$. gallolyticus provides a selective advantage to these animals, either through the metabolic transformation of gallate esters (and therefore decreased toxicity to other organisms) or the maintenance of rumen microbial biomass for the supply of bacterial protein for animal growth.

\section{ACKNOWLEDGEMENTS}

This work was supported by the Australian Council for International Agricultural Research (ACIAR) and by a scholarship to L. O. from the University of Adelaide. We would also like to thank J. McCarthy for providing excellent technical support.

\section{REFERENCES}

Bae, H. D., McAllister, T. A., Yanke, J., Cheng, K. J. \& Muir, A. D. (1993). Effects of condensed tannins on endoglucanase activity and filter paper digestion by Fibrobacter succinogenes S85. Appl Environ Microbiol 59, 2132-2138.

Barry, T. N. \& McNabb, W. C. (1999). The implications of condensed tannins on the nutritive value of temperate forages fed to ruminants. Br J Nutr 81, 263-272.

Barry, T. N. \& Manley, T. R. (1986). Interrelationships between the concentrations of total condensed tannin, free condensed tannin and lignin in Lotus sp. and their possible consequences in ruminant nutrition. J Sci Food Agric 37, 248-254.

Bernays, E. A., Cooper, D., Driver, G. \& Bilgener, M. (1989). Herbivores and plant tannins. Adv Ecol Res 19, 263-302.

Broadhurst, W. T. \& Jones, R. B. (1978). Analysis of condensed tannins using acidified vanillin. J Sci Food Agric 29, 788-794.

Brooker, J. D., O’Donovan, L. A., Skene, I., Clarke, K., Blackall, L. \& Muslera, P. (1994). Streptococcus caprinus sp. nov., a tanninresistant ruminal bacterium from feral goats. Lett Appl Microbiol 18, 313-318.

Brune, A. \& Schink, B. (1992). Phloroglucinol pathway in the strictly anaerobic Pelobacter acidigallici: fermentation of trihydroxybenzenes to acetate via triacetic acid. Arch Microbiol 157, 417-424.

Butler, L. G. (1992). Antinutritional effects of condensed and hydrolysable tannins. Basic Life Sci 59, 693-698.

Chiquette, J., Costerton, J. W., Cheng, K. J. \& Milligan, L. P. (1988). Effect of tannins on the digestibility of two isosynthetic strains of birdsfoot trefoil (Lotus corniculatus L.) using in vitro and in sacco techniques. Can J Anim Sci 68, 751-763.

Degen, A. A., Becker, K., Makkar, H. P. S. \& Borowy, N. (1995). Acacia saligna as a fodder tree for desert livestock and the interaction of its tannins with fibre fractions. J Sci Food Agric 68, $65-71$.

De Vuyst, L. \& Degeest, B. (1999). Heteropolysaccharides from lactic acid bacteria. FEMS Microbiol Rev 23, 153-77.

Evans, W. C. \& Fuchs, G. (1988). Anaerobic degradation of aromatic compounds. Annu Rev Microbiol 42, 289-317.

Frehel, C., Hellio, R., Cremieux, A. C., Contrepois, A. \& Bouvet, A. (1988). Nutritionally variant streptococci develop ultrastructural abnormalities during experimental endocarditis. Microb Pathog 4, 247-255.

Fuchs, G., Mohamed, M. E. S., Altenschmidt, U., Kock, J., Lack, A., Brackmann, R., Lochmeyer, C. \& Oswald, B. (1994). Biochemistry of anaerobic degradation of aromatic compounds. In Biochemistry of Microbial Degradation, pp. 513-553. Edited by C. Ratledge. Dordrecht: Kluwer.

Hagerman, A. E. \& Klucher, K. M. (1986). Tannin-protein interactions. Prog Clin Biol Res 213, 67-76.

Haslam, E. (1989). Plant Polyphenols - Vegetable Tannins Revisited. Cambridge, UK: Cambridge University Press.

Inoue, K. H. \& Hagerman, A. E. (1988). Determination of gallotannin with rhodanine. Anal Biochem 169, 363-369. 
Jones, G. A., McAllister, T. A., Muir, A. D. \& Cheng, K. J. (1994). Effects of Sainfoin (Onobrychis viciifolia Scop) condensed tannins on growth and proteolysis by four strains of ruminal bacteria. Appl Environ Microbiol 60, 1374-1378.

Karnovsky, M. J. (1965). A formaldehyde-glutaraldehyde fixative of high osmolarity for use in electron microscopy. J Cell Biol 27, 137-138.

Krumholz, L. R. \& Bryant, M. P. (1986). Eubacterium oxidoreducens sp. nov. requiring $\mathrm{H}_{2}$ or formate to degrade gallate, pyrogallol, phloroglucinol and quercetin. Arch Microbiol 14, 8-14.

Kumar, R. \& Singh, M. (1984). Tannins: their adverse role in ruminant nutrition. J Agric Food Chem 32, 447-453.

Kumar, R. \& Vaithiyanathan, S. (1990). Occurrence, nutritional significance and effect on animal productivity of tannins in tree leaves. Anim Feed Sci Technol 30, 21-38.

McAllister, T. A., Bae, H. D., Yanke, L. J., Cheng, K. J. \& Muir, A. (1994). Effect of condensed tannins from birdsfoot trefoil on endoglucanase activity and the digestion of cellulose filter paper by ruminal fungi. Can J Microbiol 40, 298-305.

McSweeney, C. S., Kennedy, P. M. \& John, A. (1988). Effect of ingestion of hydrolysable tannins in Terminalia oblongata on digestion in sheep fed Stylosanthes hamata. Aust J Agric Res 39, 235-244.

Mole, S. \& Waterman, P. G. A. (1987). Critical analysis of techniques for measuring tannins in ecological studies. I. Techniques for chemically defining tannins. Oecologia 72, 137-147.

Nelson, K. E., Pell, A. N., Schofield, P. \& Zinder, S. (1995). Isolation and characterisation of an anaerobic ruminal bacterium capable of degrading hydrolysable tannin. Appl Environ Microbiol 61, 3293-3298.

Nelson, K. E., Thonney, M. L., Woolston, T. K., Zinder, S. \& Pell, A. N. (1998). Phenotypic and phylogenetic characterisation of ruminal tannin-tolerant bacteria. Appl Environ Microbiol 64, 3824-3830.
Nili, N. \& Brooker, J. D. (1995). A defined medium for rumen bacteria and identification of strains impaired in de novo biosynthesis of certain amino acids. Lett Appl Microbiol 21, 69-74.

Ogimoto, K. \& Imai, S. (1984). Atlas of Rumen Microbiology. Tokyo: Japan Scientific Societies Press.

Reynolds, E. S. (1963). The use of lead citrate at high $\mathrm{pH}$ as an electron-opaque stain in electron microscopy. J Cell Biol 17, 208-212.

Skene, I. K. \& Brooker, J. D. (1995). Characterisation of tannin acylhydrolase activity in the ruminal bacterium Selenomonas ruminantium. Anaerobe 1, 321-327.

Sly, L. I., Cahill, M. M., Osawa, R., \& Fujisawa, T. (1997). The tannin-degrading species Streptococcus caprinus and Streptococcus gallolyticus are subjective synonyms. Int J Syst Bacteriol 47, 893-894.

Spurr, A. R. (1969). A low-viscosity epoxy resin-embedding medium for electron microscopy. J Ultrastruct Res 26, 31-43.

Tsai, C. G. \& Jones, G. A. (1975). Isolation and identification of rumen bacteria capable of anaerobic phloroglucinol degradation. Can J Microbiol 21, 794-801.

Waghorn, G. C., Jones, W. T., Shelton, I. D. \& McNabb, W. C. (1990). Condensed tannins and the nutritive value of herbage. Proc N Z Grassl Assoc 51, 171-176.

Whitfield, C. (1988). Bacterial extracellular polysaccharides. Can J Microbiol 34, 415-420.

Wood, C. D. \& Plumb, V. E. (1995). Evaluation of assays for phenolic compounds on the basis of in vitro gas production by rumen microorganisms. Anim Feed Sci Technol 56, 195-206.

Yan, Q. Y. \& Bennick, A. (1995). Identification of histatins as tannin-binding proteins in human saliva. Biochem J 311, 341-347.

Received 14 August 2000; revised 27 November 2000; accepted 22 December 2000 